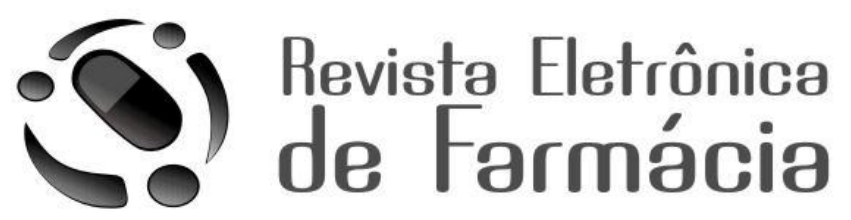

REF - ISSN 1808-0804 Vol. IX (3), 67 - 72, 2012.

\title{
MODELO EXPERIMENTAL EM ROEDORES - LIGADURA E PERFURAÇÃO CECAL
}

EXPERIMENTAL MODELS IN RODENTS - CECAL LIGATION AND PUNCTURE

MODELO EXPERIMENTAL EN ROEDORES - LIGADURA Y PUNCIÓN CECAL

\author{
Gustavo Fagotti Corrêa ${ }^{1}$ e Adriana Zapparoli ${ }^{2 *}$ \\ ${ }^{1}$ Discente de graduação em Ciências Biológicas, UNIP/UNICAMP \\ ${ }^{2}$ Pós-doutora na área de Neurofisiologia, pesquisadora e gestora da Unidade \\ Multidisciplinar de Experimentação Animal da Faculdade de Ciências Médicas da \\ Universidade Estadual de Campinas (FCM/UNICAMP) \\ *autor para correspondência: adrianazapparoli@uol.com.br
}

Recebido em 25/08/2011, Aceito em 16/08/2012.

\begin{abstract}
Resumo - Um tema que continua atual e abordado em pesquisa biomédica está associado à sepse e ao uso de antibióticos para o seu tratamento. O estudo intensivo de modelos em animais de experimentação, simulando as condições da sepse prevalentes na prática clínica ainda nos parece muito útil, e pode ser atendido em parte pelo modelo de experimentação por ligadura e perfuração cecal em roedores. O modelo CLP satisfaz os critérios para um modelo experimental, pois tem a origem polimicrobiana advinda da infecção focal, produz septicemia, libera produtos bacterianos e, ainda, promove um espectro completo de gravidade da sepse contribuindo com a investigação para novas estratégias terapêuticas.
\end{abstract}

Palavras chave: Antibiótico, Modelo CLP, Roedores. 
Corrêa, G. F.; Zapparoli, A. Revista Eletrônica de Farmácia Vol. IX (3), 67 - 72, 2012.

Abstract - A theme that continues to be of interest in biomedical research is in regard to sepsis and antibiotic use for treatment. The intensive study of experimental animal models simulating the conditions of sepsis prevalent in clinical practice still appears to be very useful. One of these models is the cecal ligation and puncture (CLP) model in rodents. CLP meets the criteria that are essential for such an experimental model: it produces a polymicrobial focal infection, resulting in septicemia, release of bacterial products, and a full spectrum of severity of sepsis in experimental animals, contributing to the development of new therapeutic strategies.

Keywords: Antibiotics, CLP Model, Rodents.

Resumen - Un tema que continúa hoy y se analiza en la investigación biomédica es el asociado a la sepsis y el uso de antibióticos para su tratamiento. El estúdio intensivo de modelos en animales de laboratorio, simulando las condiciones de la sepsis frecuente en la práctica clínica todavía parece muy útil, y puede ser desarrollado en parte por el modelo de experimentación por ligadura y punción cecal en roedores. El modelo CLP cumple con los criterios de un modelo experimental, que tiene una infección polimicrobiana, produce septicemia, liberación de productos bacterianos, y también promueve un amplio espectro de gravedad de la sepsis en la investigación que contribuyen a nuevas estrategias terapéuticas.

Palabras clave: Antibióticos, Modelo CLP, Roedores.

\section{INTRODUÇÃO}

Um tema que continua atual e abordado em pesquisa biomédica está associado a sepse e uso de antibióticos para o seu tratamento ${ }^{(1)}$. A insuficiência de múltiplos órgãos e sistemas é a mais temida e ameaçadora complicação da síndrome. Relata-se que nesses processos ocorra a ativacao maciça dos sistemas de defesa do organismo, principalmente aqueles relacionados ao sistema imune, levando à produção de grandes quantidades de mediadores inflamatórios, especialmente de citocinas (fator de necrose tumoral e as interleucinas) ${ }^{(2)}$. Quando um paciente é diagnosticado, inicia-se um tratamento de suporte intensivo seguido a administração de antibióticos segundo os critérios médicos. Por outro lado, apesar de uma despesa substancial de esforço e recurso para o desenvolvimento tecnológico de eficácia pela indústria farmacêutica, tais medidas ainda são ditas insuficientes para reduzir a freqüência de complicações associadas a mortalidade e morbidade em humanos (3) e outros animais ${ }^{(4)}$. Sendo assim, o estudo intensivo de modelos em animais de experimentação, simulando as condições da sepse prevalentes na 
Corrêa, G. F.; Zapparoli, A. Revista Eletrônica de Farmácia Vol. IX (3), 67 - 72, 2012.

prática clínica ainda nos parece muito útil que pode ser atendido em parte, pelo modelo de experimentação animal em roedores de ligadura e perfuração cecal, objetivo de descrição desse trabalho considerado relevante e pertinente na atualidade.

\section{MODELO ANIMAL EXPERIMENTAÇÃO - CLP} DE

Um modelo de experimentação animal de qualidade deve ser reprodutível, ser mínimo em variáveis e proporcionar um grande nível de detalhamento sobre um organismo ${ }^{(5)}$. Grande parte dos conhecimentos científicos para o desenvolvimento tecnológico que o homem adquiriu, visando benefícios à saúde humana e à dos animais domésticos, foi possível, em maioria, graças ao uso dos modelos de experimentação animal. Sob critérios atuais, os animais de laboratório são criados e produzidos mediante condições microbiológicas e genéticas préestabelecidas. Mantidos em ambiência controlada com monitorização regular para um controle fino de qualidade. Para atender esses parâmetros, uma área de manutenção animal deve ser padronizada com características físicas e de barreiras sanitárias especificas ${ }^{(6)}$. A maior parte dos animais usados na pesquisa brasileira, nos últimos anos, tem sido proveniente de ambiente convencional, pois a estruturação física é de baixo custo, mas de eficiência para reprodução e manutenção dos animais conforme preconiza o principio dos $3 R s$ (replacement, refinement, reduction) ${ }^{(7)}$. Por outro lado, uma parte do fracasso em se trazer novas drogas para a beira do leito pode ser atribuída, também, ao uso de modelos experimentais inadequados. Salienta-se que, por exemplo, os modelos de experimentação animal com a capacidade de reproduzirem as condições de sepse por um foco infeccioso favorecem o estudo, pois, além de mimetizarem o processo infeccioso, permitem a avaliação mais aprofundada de tratamento. Associado a essa necessidade, por outro lado, sugere-se que o modelo CLP seria o que melhor mimetizaria a natureza e o curso clínico da sepse em pacientes após trauma ${ }^{(8)}$. Realmente, o modelo de ligadura e perfuração cecal (cecal ligation and puncture - CLP) tem sido amplamente utilizado confirmadas as altas de citações disponíveis no PubMed. Justifica-se que além de proporcionarem a padronização, reprodutibilidade e versatilidade experimental necessária, por ele é possível ajustar a dose microbiana de origem mista, pela quantidade e tamanho dos furos no ceco e, com isso, um ajuste fino da modelagem de acordo com os objetivos investigativos. É possível adaptar o modelo CLP para outras espécies animais, porém camundongos e ratos com padrão sanitário SPF tenham sido usados com mais freqüência devido aos baixos custos com a manutenção e pela 
Corrêa, G. F.; Zapparoli, A. Revista Eletrônica de Farmácia Vol. IX (3), 67 - 72, 2012.

facilidade de manejo desses animais. Um esquema do procedimento do modelo CLP em roedores é mostrado na Figura 1 em uma representação esquemática publicada por Zapparoli e colaboradores em $2011^{(9)}$. Indica-se que os animais estejam em jejum, antes do procedimento cirúrgico, para criar conteúdo intestinal similar. Roedores recebem pré-indução anestésica, indução anestésica via intraperitoneal, com a cabeça do animal em uma inclinação para baixo, introduzindo-se a agulha em ângulo de vinte graus, no quarto inferior esquerdo para preservar o ceco que se encontra a direita. Após a abolição dos reflexos córneo-palpebral e podal, são colocados em mesa cirúrgica térmica e imobilizados com tensores elásticos. Procede-se a aplicação de gel oftálmico estéril durante a anestesia. (a) Após a tricotomia da face ventral da região abdominal, seguida de antissepsia com povinilpirrolidona-iodo, realiza-se 0 modelo experimental como sugerido por Wichterman e colaboradores em 1980 (10). (b) Anestesiados os animais são submetidos a uma laparotomia mediana, pela incisão de aproximadamente dois centímetros no abdômen abrangendo pele, plano músculo-aponeurótico e peritônio, expondo as vísceras abdominais; (c) $\mathrm{O}$ ceco é cuidadosamente isolado para evitar danos aos vasos sanguíneos; (d) Identificando-se e exteriorizando, (e) o ceco é ligado abaixo da válvula ileocecal com obstrução total objetivando aumentar a pressão dentro deste segmento do intestino, sem provocar isquemia, e não permitir o livre trânsito do conteúdo do intestino delgado para o intestino grosso. Após a ligadura, (f) o ceco é perfurado conforme a necessidade protocolar com agulha de punção venosa, pressionado gentilmente, para certificação de o extravasamento das fezes na cavidade abdominal, e recolocado no abdome. (g). A cavidade abdominal então é fechada em sutura realizada com fio em 2 planos: peritôniomúsculo-aponevrótico e pele.Note-se que uma ação anestésica de curta duração é usada para esse procedimento cirúrgico, a fim de minimizar os efeitos deletérios da anestesia sobre as funções cardiovasculares. Os roedores recebem analgésicos via oral (Acetominofen/Paracetamol) são colocados sob luz incandescente e, quando recuperados da anestesia, são devolvidos às suas caixas com o livre acesso a água e ração. Geralmente a recuperação é rápida após o procedimento cirúrgico.
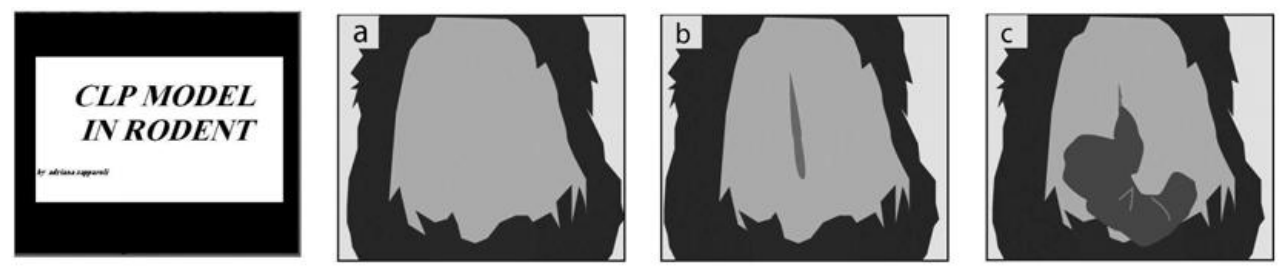

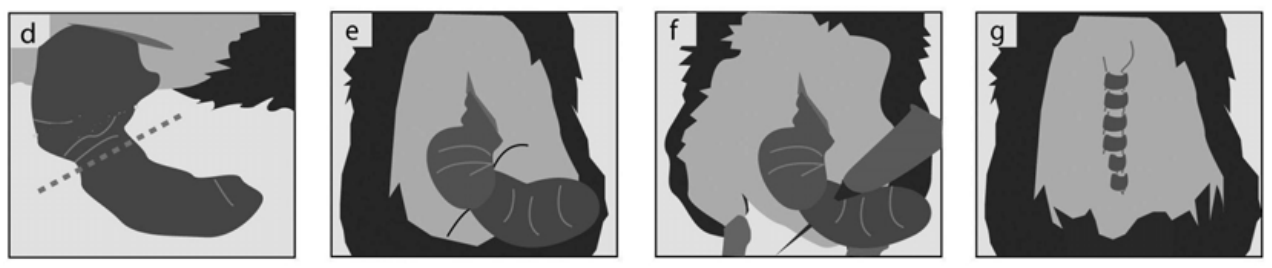

Figura 1 - Zapparoli e colaboradores em 2011. (9)

No entanto, o CLP em roedores possui algumas limitações comuns aos modelos experimentais com animais de pequeno porte. A principal delas é a incapacidade de obter amostras de sangue em série durante longos períodos de tempo para testes que consomem quantidades substanciais para avaliação. Da mesma forma, as medições fisiológicas (tal como medida e monitorização continua do débito cardíaco) são mais difíceis em um roedor se comparadas às condições de realização em animais de laboratório de médio porte os quais não necessitam de miniaturização instrumental para realização do procedimento. No entanto, as novas tecnologias estão a superar alguns destes problemas, e um relatório recente medida da função contrátil cardíaca em CLP induzida por sepse com sucesso em camundongos (11). Algumas limitações relacionadas para exames laboratoriais podem ser superadas pelo uso de um número adequado de amostra em animais e adequação metodológica de microtécnicas para análise amostral usada em medicina laboratorial. Por outro lado, disparidades entre a fisiologia humana vs. murídeos coloca algumas restrições sobre o uso de CLP. Por exemplo, a ligadura cecal sem perfuração pode ser muito bem tolerada por um roedor, conforme nossas experiências próprias do que, contrariamente, seria em seres humanos (12).

\section{CONCLUSÃO}

No caso da sepse a sobrevida do paciente é dependente da precocidade e da adequação do tratamento. Experimentalmente, o CLP satisfaz os critérios e os atributos essenciais para um modelo de experimentação de septicemia causado por trauma; não é exigente em habilidades em técnica cirúrgica, tem origem polimicrobiana de uma infecção focal e libera produtos bacterianos. Porque produz um espectro completo de gravidade da sepse, permite vasta investigação experimental inclusive para novas estratégias terapêuticas.

\section{REFERÊNCIA BIBLIOGRÁFICA}


Corrêa, G. F.; Zapparoli, A. Revista Eletrônica de Farmácia Vol. IX (3), 67 - 72, 2012.

1- Mikkelsen ME, Gaieski DF. Antibiotics in sepsis: timing, appropriateness, and (of course) timely recognition of appropriateness. Crit Care Med. 2011;39(9):2184-6;

2- Cöl R, Durgun Z. Effect of recombinant interleukin-10 on some haematological and biochemical parameters in a rat endotoxaemic model. Acta Vet Hung. 2011;59(2):23745;

3- Hubbard WJ, Choudhry M, Schwacha MG, Kerby JD, Rue LW 3rd, Bland KI, Chaudry IH. Cecal ligation and puncture. Review. Shock. 2005;24 Suppl 1:52-7;

4- Campbell VL. Respiratory complications in critical illness of small animals. Vet Clin North Am Small Anim Pract. 2011;41(4):709-16;

5- Freise H, Brückner UB, Spiegel HU. Animal models of sepsis. Review. J Invest Surg. 2001;14(4):195-212;

6- Cesarino JL, Gontijo JAR, Zapparoli A. Environment in an experimental animal facility and the species Rattus norvegicus: Review. Revista Eletrônica de Farmácia. 2011; 8: 2532 ;

7- Flecknell P. Replacement, reduction and refinement. ALTEX. 2002;19(2):73-8;

8- Sweet MJ, Hume DA. Endotoxin signal transduction in macrophages. The Journal of Leukocyte Biology.1996; 60: 08-26;

9- Zapparoli A, Colleto CA, Gontijo JAR. Evaluation of renal function in septic spontaneously hypertensive rat. Advanced Studies in Biology. 2011;3(1):01 - 11;

10- Wichterman KA, Baue $A E$, Chaudry IH. Sepsis and septic shock-a review of laboratory models and a proposal, The Journal of Surgical Research. 1980; 29: 189-201;

11- Tao W, Deyo DJ, Traber DL, Johnston WE, Sherwood ER. Hemodynamic and cardiac contractile function during sepsis caused by cecal ligation and puncture in mice. Shock. 2004;21(1):31-7;

12- Rittirsch D, Hoesel LM, Ward PA. The disconnect between animal models of sepsis and human sepsis. Review. J Leukoc Biol. 2007;81(1):137-43. 